\title{
Utilisation of Glass for the Production of Inorganic Polymeric Materials for Construction Industry
}

\author{
Thomas Parisis, Nicole Mavrovounioti, Panayiotis Antoniades \\ Stratagem Energy Ltd., Limassol, Cyprus \\ Email: tp@stratagem.com.cy
}

How to cite this paper: Parisis, T., Mavrovounioti, N. and Antoniades, P. (2020) Utilisation of Glass for the Production of Inorganic Polymeric Materials for Construction Industry. Open Access Library Journal, 7: e6123.

https://doi.org/10.4236/oalib.1106123

Received: January 30, 2020

Accepted: April 20, 2020

Published: April 23, 2020

Copyright $\odot 2020$ by author(s) and Open Access Library Inc.

This work is licensed under the Creative

Commons Attribution International

License (CC BY 4.0).

http://creativecommons.org/licenses/by/4.0/

\begin{abstract}
This paper deals with the utilisation of glass coming from municipal waste mainly for the production of inorganic polymeric materials, with advanced mechanical properties, intended for the construction industry. The development of glass-based geopolymers, achieving high compressive strength and low water absorption, is described, and the produced materials are compared with some common construction and building materials.
\end{abstract}

\section{Subject Areas \\ Composite Material, Material Experiment}

\section{Keywords}

Geopolymers, Construction Materials, Glass

\section{Introduction}

As it is well known, solid wastes cause severe contamination of the air, soil and surface and ground-water bodies. According to the EC Directive 96/61/EC [1], laid down for the management of wastes and by-products, their recycling, as well as their re-use as secondary raw materials, is strongly encouraged, in order to eliminate and/or prevent the environmental pollution, protect the human's health and preserve the natural resources. In this direction, an extended research, aiming at the development of viable technologies for the utilisation of industrial solid wastes and by-products in the production of useful materials, is performed during the last decades.

The geopolymerization technology [2] and therefore the study of the properties of the materials produced that are called geopolymers are an issue of 
on-going extensive research worldwide. Geopolymers are a class of aluminosilicate-based materials with the potential to replace Portland cement in a variety of applications, particularly where chemical or thermal resistance is required [3]. Geopolymers are formed by the reaction between an alkaline solution and an aluminosilicate source. The hardened material has an amorphous to semi-crystalline three-dimensional structure similar to that of an aluminosilicate glass [4]. The reaction is exothermic and takes place at atmospheric pressure and temperatures below $100^{\circ} \mathrm{C}$ [2] [5]. The most proposed mechanisms for the geopolymerization process [5] [6] include the following four stages that proceed in parallel and thus, it is difficult to be distinguished: 1) Si and Al dissolution from the solid alumino-silicate materials in a strongly alkaline aqueous solution, 2) formation of oligomers (polynuclear hydroxy-complexes of silicon and aluminium) consisting of polymeric bonds of $\mathrm{Si}-\mathrm{O}-\mathrm{Si}$ and $\mathrm{SiO}-\mathrm{Al}$ type, 3) polycondensation of the oligomers to form a three-dimensional aluminosilicate framework (geopolymeric framework) comprising of $\mathrm{SiO}_{4}$ and/or $\mathrm{AlO}_{4}$ tetrahedra linked alternately by sharing common oxygen ions and 4) bonding of the non-dissolved solid particles into the geopolymeric framework and hardening of the whole system into a final solid polymeric material.

Geopolymers possess excellent physicochemical and mechanical properties, like low density, micro- or nano-porosity, negligible shrinkage, high mechanical strength, thermal stability, fire resistance as well as chemical resistance, and notable surface hardness [2] [5] [7] [8] [9]. Due to these properties, geopolymers are often viewed as alternatives for certain industrial applications in the area of construction and building materials, since their properties are often similar to or even better than those of the conventional construction and fire protection materials. Apart from that, geopolymers seem to be more attractive than the conventional materials due to their low production cost, the lower energy requirements for production and the rational utilization of natural resources. This latter feature makes the geopolymerization technology very attractive as it achieves to turn numerous industrial by-products into added value materials [5] [7]-[13] and to offer possible technological solutions for the effective stabilization of hazardous wastes [14] [15], as well as for the encapsulation of toxic and radioactive wastes [6], contributing significantly to the elimination and/or reduction of the environmental pollution.

This paper aims at studying the geopolymerization of the glass coming from municipal wastes generated in order to develop novel inorganic polymeric materials for construction purposes. One of the main issues for the construction materials is the combination of high mechanical strength and low water absorption.

\section{Experimental}

\subsection{Materials}

The chemical analysis of the glass is given in Table 1. The X-ray Fluorescence (XRF) method (Spectro Xepos-Standardized for Aluminosilicate materials) was 
used to determine the chemical composition of the glass. As shown in Table 1, the glass is very rich in silicon oxides and is relatively high in sodium, calcium and magnesium oxides.

The mineralogical analysis of the glass was performed according to the X-ray diffraction method on a SIEMENS D5000 diffractometer. As can be seen from Figure 1, the glass consists essentially of an amorphous silicate phase which is typical of glassy materials.

\subsection{Synthesis of the Geopolymers}

The following series of experiments were performed to study the behavior of glass geopolymers. It should be mentioned that $\mathrm{NaOH}$ was used as alkaline activator instead of $\mathrm{KOH}$, and the reason is that the final application of the materials must show materials with high mechanical properties. $\mathrm{NaOH}$ as the most active solubilizes the amorphous $\mathrm{Si}$ and $\mathrm{Al}$ in the solid raw material to create a more stable mesh.

The first set of experiments concerns the study of the effect of alkali concentration on the strength of the finished material, with values of $6 \mathrm{M}, 8 \mathrm{M}, 10 \mathrm{M}$ and $12 \mathrm{M}$. The purpose of the materials produced is to develop a compressive strength of at least $10 \mathrm{MPa}$, which is considered suitable for use as a sidewalk slab. The hardening temperatures of the geopolymers selected for experimental study in this series of experiments were $60^{\circ} \mathrm{C}$. In all experiments, the relative maturation humidity of the geopolymers was $70 \%$.

The methodology used to synthesize all the geopolymers used for the experimental study was as follows:

Initially, sodium hydroxide was dissolved in deionized water and the solid phase of the system (glass) was added in part and under constant mechanical stirring. The two phases were mechanically mixed for an additional $5 \mathrm{~min}$, until a homogeneous slurry was created. Due to the low liquid phase content in the system, since the solid-to-liquid ratio $(\mathrm{S} / \mathrm{L})$ was $\mathrm{S} / \mathrm{L}=4 \mathrm{~g} / \mathrm{mL}$, the slurry generated was highly viscous. The synthesis followed is the one shown in Table 2.

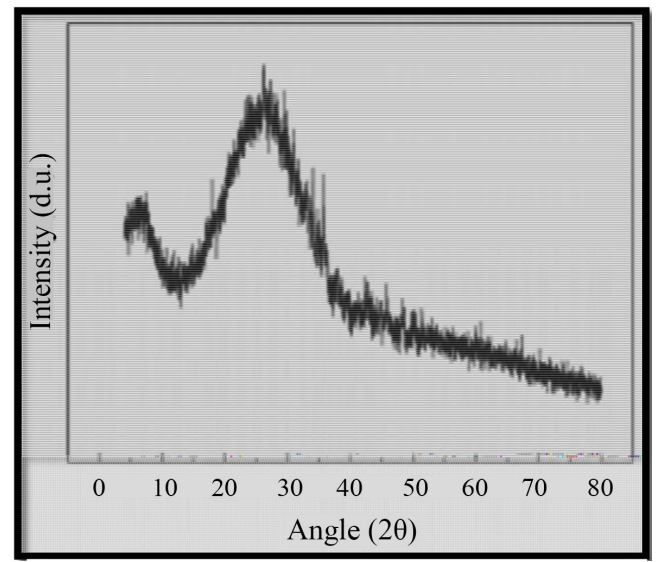

Figure 1. Mineralogical analysis of glass. 
Table 1. Chemical analysis of glass.

\begin{tabular}{cc}
\hline Oxides & XRF Method \\
\hline $\mathrm{SiO}_{2}$ & 68.9 \\
$\mathrm{Al}_{2} \mathrm{O}_{3}$ & 0.6 \\
$\mathrm{Na}_{2} \mathrm{O}$ & 13.2 \\
$\mathrm{MgO}$ & 2.6 \\
$\mathrm{CaO}$ & 11.22 \\
\hline
\end{tabular}

Table 2. Geopolymer synthesis conditions.

\begin{tabular}{ccc}
\hline Synthetic Ingredient & Mass $(\mathrm{g})$ & Content (wt\%) \\
\hline Glass & 800.00 & 79.22 \\
Sodium hydroxide & 27.89 & 2.76 \\
Deionized water & 150.31 & 18.02 \\
Total & 1009.89 & 100 \\
\hline
\end{tabular}

\subsection{Formatting of Geopolymers}

The glass was mixed with an alkaline sodium silicate solution $\left(\mathrm{NaOH}\right.$ and $\left.\mathrm{SiO}_{2}\right)$, used as an aqueous activator, in order to create a viscous paste that was subsequently molded in cubic $50 \times 50 \times 50 \mathrm{~mm}$ molds and cured in a laboratory-scale oven for 72 hours, under atmospheric pressure, temperature $60^{\circ} \mathrm{C}$ and relative humidity $70 \%$. The formed cubic specimens were kept in closed molds for the first six hours of curing. Thereafter, they were demolded and left in the oven until curing. The cured specimens were left to cool for 48 hours at ambient conditions, before any test and analysis was carried out. The compressive strength according to ASTM C-109 and the cold water absorption according to the EN 771-1:2003 standard tests were determined.

\subsection{Results and Discussion}

After the geopolymer hardening, their apparent density, water absorption and alkalinity were tested. For the apparent density measurements, all three geopolymer specimens of each experiment were used. The water absorption test was subjected to one of the three geopolymer specimens of each experiment. The alkalinity of the geopolymers was measured in parallel with the water absorption, while the stability of the geopolymers was also studied in the same test.

Table 3 summarizes the results of the measurements of the properties of the geopolymers after their ripening at various temperatures.

As illustrated in Table 3, the apparent density of geopolymers is directly affected by alkalinity and increases as alkalinity increases. The water absorption of geopolymers by glass was extremely low compared to that of various conventional materials used today in the building materials and construction sectors. In the water absorption test, the geopolymers of all the experiments maintained their shape and consistency and did not undergo any external changes. 
Table 3. Properties of geopolymers.

\begin{tabular}{ccccc}
\hline Alkalinity $(\mathrm{M})$ & Density $\left(\mathrm{Kg} / \mathrm{m}^{3}\right)$ & Water Absorption (\%) & \multicolumn{2}{c}{$\mathrm{pH}$ Initial Final } \\
\hline $\mathbf{6}$ & 1521.85 & 1.01 & 6.65 & 11.137 \\
$\mathbf{8}$ & 1591.00 & 0.84 & 5.55 & 11.557 \\
10 & 1692.21 & 0.79 & 6.38 & 11.195 \\
12 & 1734.42 & 0.77 & 6.24 & 11.104 \\
\hline
\end{tabular}

The geopolymers of all the experiments showed high alkalinity and remained unchanged after being in water for 24 hours. In general, geopolymers are highly alkaline materials due to the high concentration of sodium hydroxide in their mass and the unreacted free alkali.

In addition of the synthesis conditions of the geopolymers followed in this experimental study, the appearance of the specimens is not directly affected by the alkali concentration.

\subsection{Mechanical Strengths of Geopolymers}

Upon the completion of hardening of the geopolymers (28 days) at the temperatures studied, two of the three geopolymer specimens of each experiment were subjected to uniaxial compression after being kept at ambient conditions for 24 hours. The average strength measurements of these specimens were considered as the ultimate mechanical strength of the geopolymers at the corresponding curing temperature.

As shown in Figure 2, the ultimate mechanical strength of the geopolymers is illustrated as a function of their alkalinity and their ultimate resistance in uniaxial compression appears to be substantially affected by alkalinity. Moreover, the increase in alkalinity results in a decrease-stabilization of the mechanical strength of the geopolymers and this was due to the excessive amount of $\mathrm{NaOH}$ in the system relative to the amorphous silicon and aluminium contained in the raw material. The alkalinity of $10 \mathrm{M}$ is obviously the maximum amount of alkali that can dissolve the insoluble silicon particles in the glass.

More specifically, the total strength increased as the initial $\mathrm{NaOH}$ concentration increased from $6 \mathrm{M}$ to $10 \mathrm{M}$, reaching a maximum value of $28 \mathrm{MPa}$. Further increase of the initial $\mathrm{NaOH}$ concentration to $12 \mathrm{M}$ resulted in a decrease in the competitive force. Sodium hydroxide is concentrated in the alkaline wash of the glass in order to remove soluble amounts of silicon and aluminium from the glass. The rate of this divergence is directly related to the concentration of hydroxide ions in the liquid phase and generally increases with the increase of these ions. Increased concentrations of $\mathrm{Si}$ and $\mathrm{Al}$ in the liquid phase are necessary to maintain the oligomers of $\mathrm{Si}$ and $\mathrm{Al}$ complex species. The creation of such species accelerates the process of polycondensation which results in the development of complex polymer structures (Figure 3) that are important for the development of geopolymers. As shown in Figure 4, the increased $\mathrm{SiO}_{2} / \mathrm{Na}_{2} \mathrm{O}$ mass ratio in the liquid phase, promotes the polycondensation and polymer binder phenomena, thus, increasing the compressive strengths of the geopoly- 
mers. An excessive amount of $\mathrm{NaOH}$ in the liquid phase reduces the $\mathrm{SiO}_{2} / \mathrm{Na}_{2} \mathrm{O}$ mass ratio and inhibits the polymerization and shaping process of the polymeric binder by reducing the compressive strength of the geometric polymers.

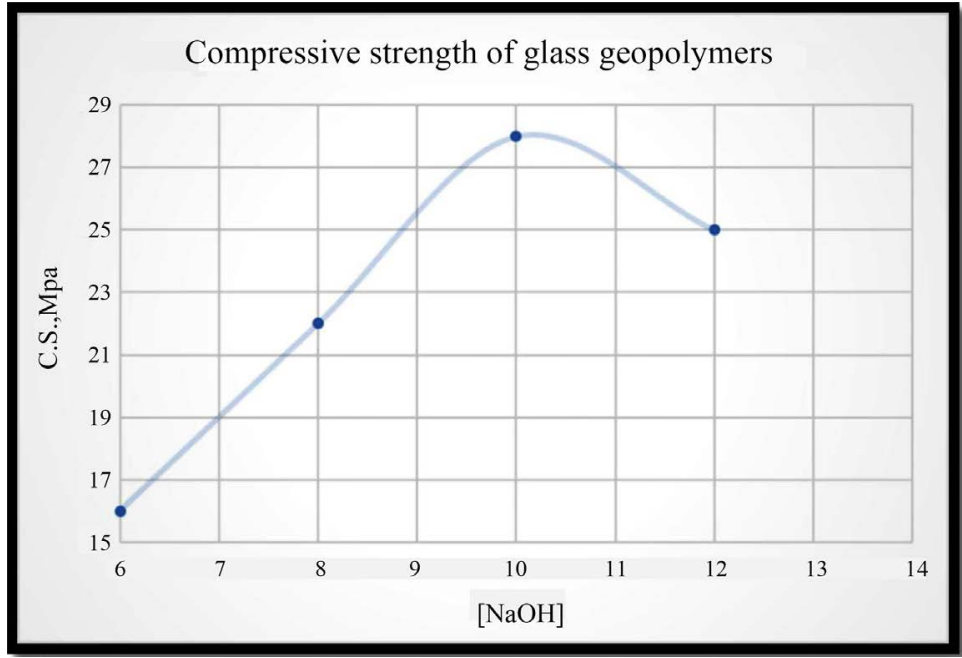

Figure 2. Resistance of geopolymers to uniaxial compression ( $\mathrm{MPa})$ as a function of alkalinity.

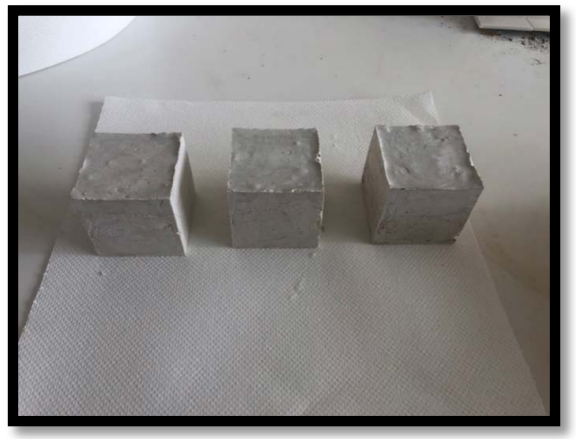

Figure 3. Glass based geopolymer.

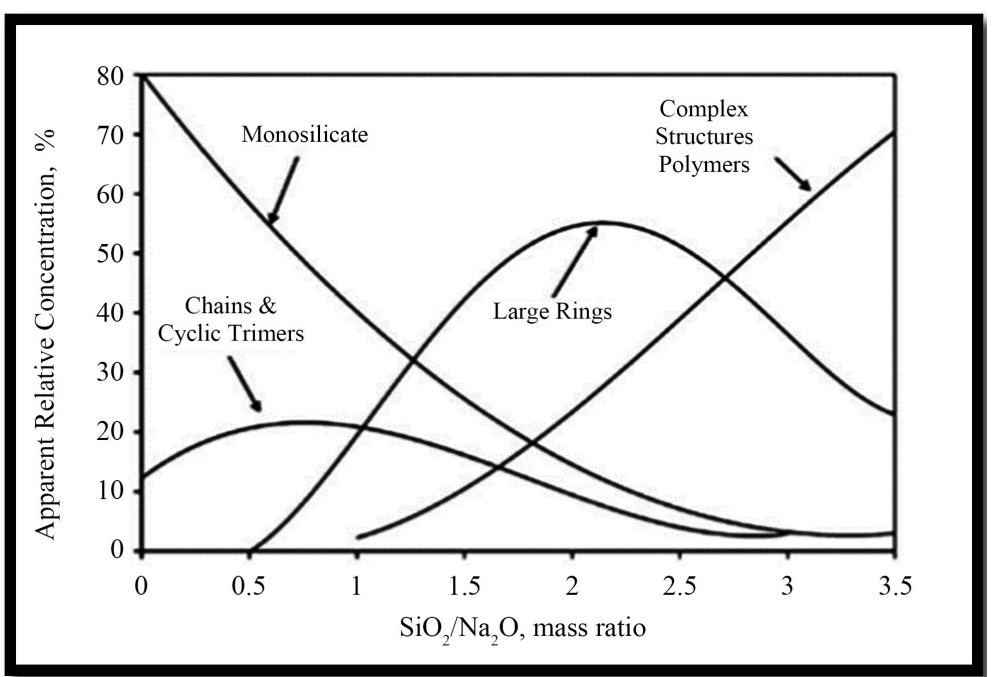

Figure 4. Structures depending on $\mathrm{SiO}_{2} / \mathrm{Na}_{2} \mathrm{O}$ ratio. 
In the uniaxial compressive strength test, the geopolymer specimens of all the experiments were not disassembled, confirming the existence of a stable, compact and cohesive structure, while behaving like natural rocks, forming a characteristic angle of $45^{\circ}$ when they break.

\section{Conclusions}

In this work the development of added value geopolymer materials, using glass as raw material, is described.

1) Geopolymer material achieved a $28 \mathrm{MPa}$ compressive strength with a $<1 \%$ water absorption. This material has comparable or superior properties in relation to the commonly used construction materials (normal and high strength concretes).

2) The increase of alkalinity did not result in higher compressive strength.

\section{Conflicts of Interest}

The authors declare no conflicts of interest regarding the publication of this paper.

\section{References}

[1] European Commission (1996) Council Directive 96/61/EC of 24 September 1996 Concerning Integrated Pollution Prevention and Control. Official Journal L, 257, 26-40.

[2] Davidovits, J. (1999) Geopolymer. 2nd International Conference, Saint-Quentin, 9-39.

[3] Provis, J., Duxson, P., Harrex, R.M., Yong, C.Z. and Van Deventer, J.S.J. (2009) Valorisation of Fly Ashes by Geopolymerisation. Global Nest Journal, 11, 147-154. https://doi.org/10.30955/gnj.000588

[4] Van Deventer, J.G.S., Van Deventer, J.S.J. and Lukey, G.C. (2002) The Effect of Composition and Temperature on the Properties of Fly Ash- and Kaolinite-Based Geopolymers. Chemical Engineering Journal, 89, 63-73. https://doi.org/10.1016/S1385-8947(02)00025-6

[5] Swanepoel, J.C. and Strydom, C.A. (2002) Utilization of Fly Ash in a Geopolymeric Material. Applied Geochemistry, 17, 1143-1148. https://doi.org/10.1016/S0883-2927(02)00005-7

[6] Palomo, A., Grutzeck, M.W. and Blanco, M.T. (1999) Alkali-Activated Fly Ashes: A Cement for the Future. Cement and Concrete Research, 29, 1323-1329.

https://doi.org/10.1016/S0008-8846(98)00243-9

[7] Cheng, T.W. and Chiu, J.P. (2003) Fire Resistant Geopolymer Produced by Granulated Blast Furnace Slag. Journal of Minerals Engineering, 16, 205-210. https://doi.org/10.1016/S0892-6875(03)00008-6

[8] Maragos, I., Giannopoulou, I. and Panias, D. (2008) Synthesis of Ferronickel Slag-Based Geopolymers. Journal of Minerals Engineering, 22, 196-203. https://doi.org/10.1016/j.mineng.2008.07.003

[9] Bakharev, T. (2005) Geopolymeric Materials Prepared Using Class F Fly Ash and Elevated Temperature Curing. Cement and Concrete Research, 35, 1224-1232. https://doi.org/10.1016/j.cemconres.2004.06.031 
[10] Panias, D., Giannopoulou, I. and Perraki, Th. (2007) Effect of Synthesis Parameters on the Mechanical Properties of Fly Ash-Based Geopolymers. Colloids and Surfaces A: Physicochemical and Engineering Aspect, 301, 246-254. https://doi.org/10.1016/j.colsurfa.2006.12.064

[11] Xu, H. and Van Deventer, J.S.J. (2000) The Geopolymerization of Alumino-Silicate Minerals. International Journal of Mineral Processing, 59, 247-266. https://doi.org/10.1016/S0301-7516(99)00074-5

[12] Komnitsas, K., Zaharaki, D. and Perdikatsis, V. (2007) Geopolymerization of Low Calcium Ferronickel Slags. Journal of Materials Science, 42, 3073-3082. https://doi.org/10.1007/s10853-006-0529-2

[13] Bankowski, P., Zou, L. and Hodges, R. (2004) Reduction of Metal Leaching in Brown Coal Fly Ash Using Geopolymers. Journal of Hazardous Materials, 114, 59-67. https://doi.org/10.1016/j.jhazmat.2004.06.034

[14] Davidovits, J. (2011) Geopolymer Chemistry and Applications. 3rd Edition, Institut Geopolymere, Saint-Quentin.

[15] Onisei, S., Pontikes, Y., Van Gerven, T., Angelopoulos, G.N., Velea, T., Predica, V. and Moldovan, P. (2012) Synthesis of Inorganic Polymers Using Fly Ash and Primary Lead Slag. Journal of Hazardous Materials, 205-206, 101-110.

https://doi.org/10.1016/j.jhazmat.2011.12.039 